Introduction to Food Manufacturing Engineering 

Tze Loon Neoh • Shuji Adachi • Takeshi Furuta

\section{Introduction to Food Manufacturing Engineering}

辇 Springer 
Tze Loon Neoh

Okawara Mfg. Co., Ltd.

Shizuoka, Japan

Takeshi Furuta

Graduate School of Engineering

Tottori University

Tottori, Japan
Shuji Adachi

Graduate School of Agriculture

Kyoto University

Kyoto, Japan

ISBN 978-981-10-0441-4

ISBN 978-981-10-0442-1 (eBook)

DOI 10.1007/978-981-10-0442-1

Library of Congress Control Number: 2016944013

C Springer Science+Business Media Singapore 2016

This work is subject to copyright. All rights are reserved by the Publisher, whether the whole or part of the material is concerned, specifically the rights of translation, reprinting, reuse of illustrations, recitation, broadcasting, reproduction on microfilms or in any other physical way, and transmission or information storage and retrieval, electronic adaptation, computer software, or by similar or dissimilar methodology now known or hereafter developed.

The use of general descriptive names, registered names, trademarks, service marks, etc. in this publication does not imply, even in the absence of a specific statement, that such names are exempt from the relevant protective laws and regulations and therefore free for general use.

The publisher, the authors and the editors are safe to assume that the advice and information in this book are believed to be true and accurate at the date of publication. Neither the publisher nor the authors or the editors give a warranty, express or implied, with respect to the material contained herein or for any errors or omissions that may have been made.

Printed on acid-free paper

This Springer imprint is published by Springer Nature

The registered company is Springer Science+Business Media Singapore Pte Ltd. 
To the memory of my father; to my wife, Patricia, for her unconditional support; and to my family.

T.L.N. 



\section{Preface}

Food science refers to an integrated science, encompassing comprehensive aspects of the processing of all sorts of bioresources including agricultural, livestock, and marine products into food or food ingredients. Also included are the methods of preparation as well as the effects on the human body resulting from the ingestion of the prepared food products, and in this way food science contributes to the betterment of health and the enrichment of life for mankind. In order to achieve these ultimate goals, food-manufacturing knowledge for processing bioresources into food and food ingredients is therefore indispensable.

The discipline of food manufacturing includes both food processing or food technology, which refers to the study of the objectives and principles of the respective unit processes along the production flow of a food or food ingredient; and also food engineering, which covers the study of a long list of principles common for operations in food-manufacturing processes such as heating and agitation. The former study conforms to actual food-manufacturing flows and thus is readily comprehensible, whereas the latter has high versatility covering the common principles of operations for most food-manufacturing processes. Although many textbooks on food processing are easily accessible, textbooks on food engineering are scarce at the present time, and even those available on the market include a vast array of topics and thus many of them are unsuitable for beginners. Hence, a simple textbook intended for undergraduate students majoring in food-related disciplines other than engineering - for instance, food science, food technology, or nutritionis highly desirable.

From the standpoint of academics and researchers in the fields of agriculture and engineering, we therefore drew up a plan for this particular book for undergraduate students studying agriculture and engineering. This volume is meant to be an introduction to food engineering in which common principles for foodmanufacturing-process operations are taught. Food engineering itself is rather an abstract and hard-to-understand discipline. Therefore, we have endeavored to initially set forth food-manufacturing flows and pay careful attention to quantitatively detailing and explaining the manufacturing operations involved from an engineering point of view. Because the text is considered an "extreme" introductory book to 
food engineering for beginners, it does not cover all food-engineering-related fields. Rather, it is written for its readership to gain an engineering perspective on the subject and consolidate the foundation of knowledge such that the readers, when necessary, can better understand other more structured and systematically written textbooks on food engineering.

Food engineering deals with a great number of mathematical formulas and numerical values. Because it is difficult for one to acquire such knowledge merely through reading, we have focused on introducing as many example problems and exercises as possible. Furthermore, in many cases graphic representation of data better explains a phenomenon, making it simpler to understand. Graph construction is the most basic but it is seldom covered in lectures at university level, resulting in many students not being able to draw proper graphs. We have illustrated how proper figures are produced and included many sample questions and exercises of which the solutions are obtainable from constructed figures. When it comes to dealing with mathematical formulas and numerical values, practicing problem solving will definitely foster a better understanding, and it is of utmost importance to actually try to put the graphs on paper. Although it has become common for these problemsolving steps to be done on a computer nowadays, one could hardly get a good grasp of the knowledge by just tapping the keyboard and looking at the monitor. On that account, a great deal of thought has been put into selecting the sample questions and exercises such that solving the problems will necessitate sketching and computing with a scientific calculator.

In food engineering, one studies the common principles for process operations, and the knowledge is not limited to food manufacturing but is applicable as well in other areas-for instance, the chemical, pharmaceutical, and environmental industries. Readers are expected to acquire the basic concepts through this textbook and subsequently further deepen the level of understanding via other systematic reference materials.

Shizuoka, Japan

Tze Loon Neoh

Kyoto, Japan

Shuji Adachi

Tottori, Japan

Takeshi Furuta

March 2016 


\section{Contents}

1 Contributions of Food Engineering to Everyday Meals ............. 1

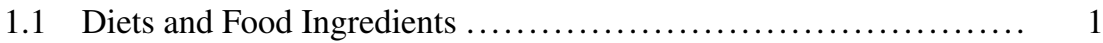

1.2 Common Operations in Preparation of Food/Food Ingredients ...... 2

1.3 Primary Unit Operations .................................... 6

1.4 Facing the Challenge ......................................... 9

Exercise $\ldots \ldots \ldots \ldots \ldots \ldots \ldots \ldots \ldots \ldots \ldots \ldots \ldots \ldots \ldots \ldots \ldots \ldots \ldots \ldots \ldots, 10$

2 Bookkeeping of a Process $\ldots \ldots \ldots \ldots \ldots \ldots \ldots \ldots \ldots \ldots \ldots \ldots \ldots \ldots \ldots \ldots \ldots, 11$

2.1 Units .................................................... 11

2.2 Mass Balance............................................. 13

2.2.1 Mass Balance: Meaning and Significance ................ 13

2.2.2 Calculation Steps of Mass Balance ..................... 14

2.2.3 Mass Balance of Unsteady-State Process.................. 18

2.3 Analysis and Presentation of Data ........................ 24

2.3.1 Logarithmic Manipulation of Data........................ 24

2.3.2 How to Draw a Graph ............................. 27

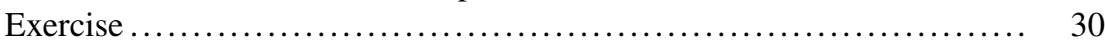

3 Wheat Flours and Their Derived Products ....................... 35

3.1 Classification of Wheat Flours and Their Applications ........... 35

3.2 Particle Size of Wheat Flours ............................. 36

3.2.1 Characteristic Diameter .......................... 36

3.2.2 Particle-Size Distribution ........................... 40

3.2.3 Mean Particle Size ................................... 45

3.3 Texture of Breads .......................................... 47

3.3.1 Stress-Strain Curve ................................. 47

3.3.2 Elastic Solids and Hooke's Law ...................... 49

3.3.3 Rupture Stress and Rupture Energy ................... 50

3.4 Spaghetti.............................................. 52

3.4.1 Water Activity ..................................... 53

3.4.2 Moisture Sorption Isotherm ........................ 56 
3.4.3 Hot Air-Drying................................... 58

3.4.4 Glass Transition...................................... 60

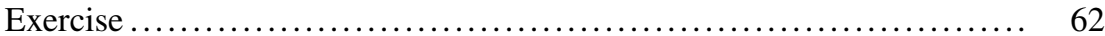

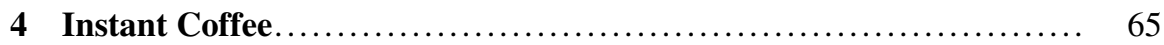

4.1 Manufacturing Processes of Instant Coffee .................... 65

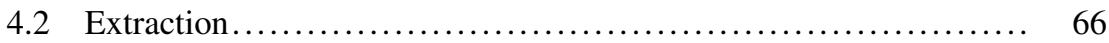

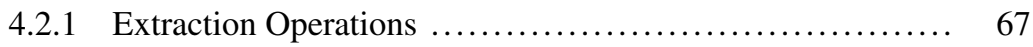

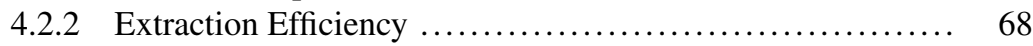

4.2 .3 Extraction Rate.................................. 71

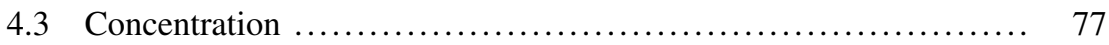

4.3.1 Concentration Equipment ......................... 77

4.3.2 Design of Concentration Equipment ................. 78

4.4 Spray-Drying and Freeze-Drying $\ldots \ldots \ldots \ldots \ldots \ldots \ldots \ldots \ldots \ldots \ldots \ldots \ldots \ldots \ldots$

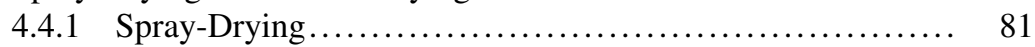

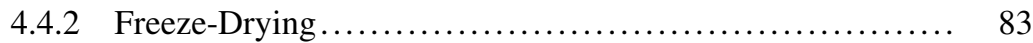

4.4.3 Calculation for Design of Dryer ..................... 84

4.4.4 Mass Balance of a Dryer ............................ 87

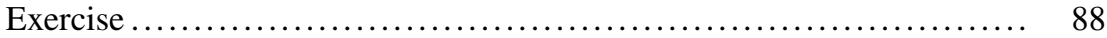

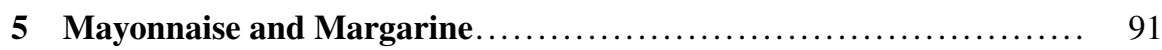

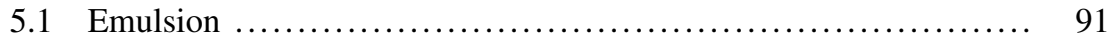

5.1.1 Classification of Emulsion ........................... 91

5.1.2 Emulsification Operation and Equipment .............. 92

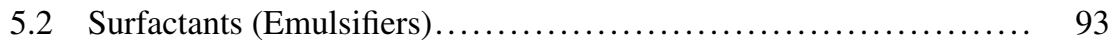

5.2.1 Characteristics of Surfactants ....................... 93

5.2 .2 HLB Value $\ldots \ldots \ldots \ldots \ldots \ldots \ldots \ldots \ldots \ldots \ldots \ldots \ldots \ldots . \ldots 7$

5.2.3 Minimum Energy for Emulsification .................. 98

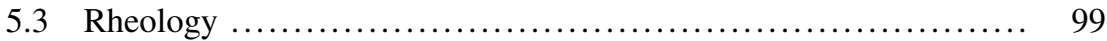

5.3.1 Newton's Law of Viscosity........................ 99

5.3.2 Measurement of Viscosity .......................... 101

5.3.3 Flow Curve ........................................ 102

5.3 .4 Viscoelastic Fluids .............................. 105

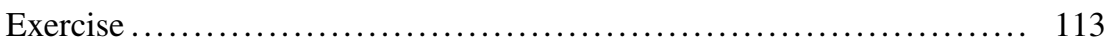

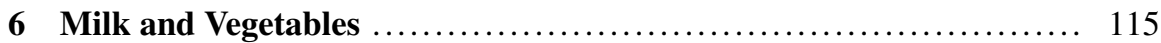

6.1 Deterioration and Preservation of Food ...................... 115

6.1.1 Quality Deterioration of Food ....................... 115

6.1.2 Preservation of Food ................................ 116

6.2 Sterilization of Milk .................................. 117

6.2.1 Microbial Death Kinetics ........................... 117

6.2.2 Temperature Dependence of Microbial Death Rate ......... 119

6.2.3 Flash Pasteurization (High Temperature and Short Time) .... 122

6.2.4 Heat Exchanger ................................ 126 
6.3 Low-Temperature Storage of Produce ....................... 139

6.3.1 Reasons for Low-Temperature Storage of Fresh Foods ....... 139

6.3.2 Refrigeration and Freezing Systems ................... 139

6.3.3 Refrigeration and Refrigeration Time of Fruits/Vegetables... 141

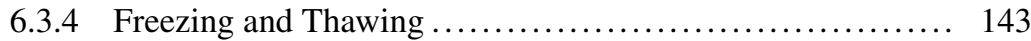

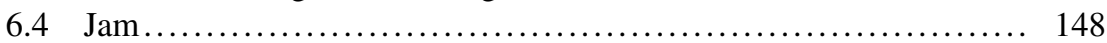

6.4.1 Manufacturing Process of Jam ....................... 148

6.4.2 Water Activity and Quality Deterioration of Foods ......... 150

6.4.3 Intermediate-Moisture Foods ........................ 154

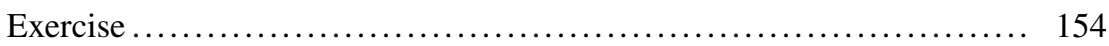

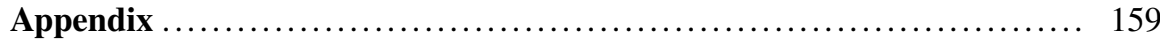

A1 Expressions of Concentration .............................. 159

A2 Graphical and Numerical Calculus ......................... 160

A2.1 Graphical Integration ............................ 160

A2.2 Numerical Integration .............................. 161

A2.3 Graphical Differentiation ........................... 164

A2.4 Numerical Differentiation .............................. 164

A3 Variables Separable Differential Equations .................... 166

A4 Estimation of Parameters with Microsoft Excel ${ }^{\circledR}$................. 168

Major Physical Constants ...................................... 175

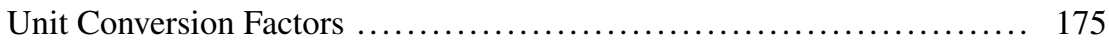

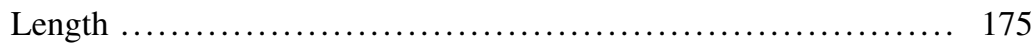

Mass .............................................. 175

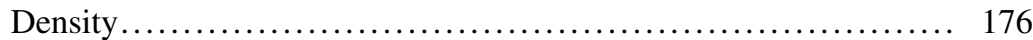

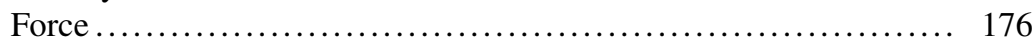

Pressure .................................................. 176

Energy, Work, and Heat................................... 176

Power ............................................... 177

Thermal Conductivity .................................. 177

Heat Transfer Coefficient ..................................... 177

Viscosity ............................................. 177

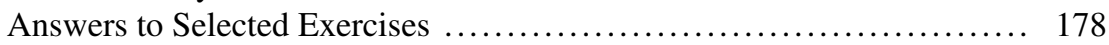

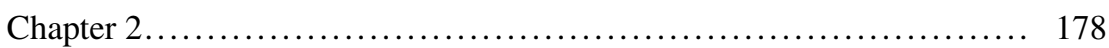

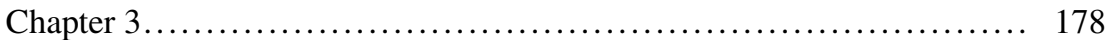

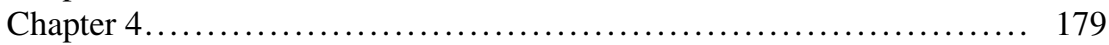

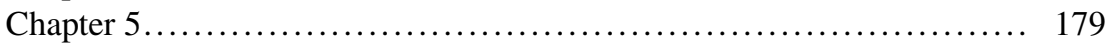

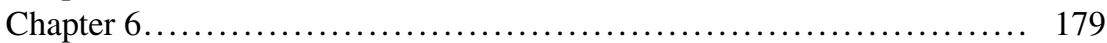

